\title{
ARD
}

\section{Evaluation of work-related psychosocial factors and regional musculoskeletal pain: results from a EULAR Task Force}

G J Macfarlane, N Pallewatte, P Paudyal, et al.

Ann Rheum Dis 2009 68: 885-891 originally published online August 22, 2008

doi: 10.1136/ard.2008.090829

Updated information and services can be found at:

http://ard.bmj.com/content/68/6/885.full.html

\section{These include:}

References This article cites 36 articles, 10 of which can be accessed free at: http://ard.bmj.com/content/68/6/885.full.html\#ref-list-1

Article cited in:

http://ard.bmj.com/content/68/6/885.full.html\#related-urls

Email alerting Receive free email alerts when new articles cite this article. Sign up in the service box at the top right corner of the online article.

Topic collections Articles on similar topics can be found in the following collections

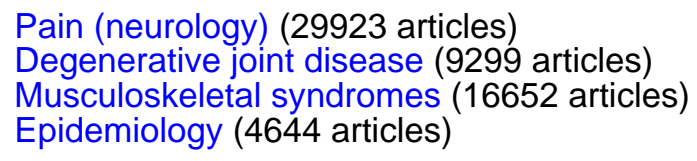

Notes

To order reprints of this article go to:

http://ard.bmj.com/cgi/reprintform

To subscribe to Annals of the Rheumatic Diseases go to:

http://ard.bmj.com/subscriptions 


\title{
Evaluation of work-related psychosocial factors and regional musculoskeletal pain: results from a EULAR Task Force
}

\author{
G J Macfarlane, ${ }^{1}$ N Pallewatte, ${ }^{1}$ P Paudyal, ${ }^{1}$ F M Blyth, ${ }^{1,2}$ D Coggon, ${ }^{3}$ G Crombez, ${ }^{4}$ \\ S Linton, ${ }^{5} \mathrm{P}$ Leino-Arjas, ${ }^{6} \mathrm{~A}$ J Silman, ${ }^{7} \mathrm{R}$ J Smeets, ${ }^{8} \mathrm{D}$ van der Windt ${ }^{9,10}$
}

${ }^{1}$ Aberdeen Pain Research Collaboration (Epidemiology Group), University of Aberdeen, Aberdeen, Scotland, UK;

${ }^{2}$ University of Sydney Pain Management \& Research Institute, Royal North Shore Hospital, Sydney, Australia;

${ }^{3}$ MRC Epidemiology Resource

Centre, University of

Southampton, Southampton,

UK; ${ }^{4}$ Department of Experimental-Clinical and Health Psychology, Ghent University, Ghent, Belgium; ${ }^{5}$ Departments of Behavioral, Social and Legal Sciences and Psychology, Örebro University, Örebro, Sweden; ${ }^{6}$ Finnish Institute of Occupational Health, Helsinki Finland; ${ }^{7}$ Arthritis Research Campaign, Chesterfield, UK;

${ }^{8}$ Rehabilitation Centre Blixembosch, Eindhoven, and School for Public Health and Primary Care (CAPHRI), University of Maastricht, Maastricht, The Netherlands;

${ }^{9}$ EMGO Institute, VU Medical Centre, Amsterdam, The Netherlands: ${ }^{10}$ Primary Care Musculoskeletal Research Centre, University of Keele, Newcastle-under-Lyme, UK

Correspondence to: Professor G J Macfarlane, Epidemiology Group, Department of Public Health, School of Medicine, University of

Aberdeen, Polwarth Building Foresterhill, Aberdeen, AB25

2ZD, Scotland, UK; g.j.

macfarlane@abdn.ac.uk

Accepted 9 July 2008

Published Online First

22 August 2008

\section{ABSTRACT}

Objectives: To establish whether review articles provide consistent conclusions on associations between workplace psychosocial factors and musculoskeletal pain and, if differences exist, to explore whether this is related to the methods used

Methods: Reviews, reported up to February 2007, that included consideration of workplace psychosocial factors and upper limb, back or knee pain were identified through searches of multiple databases. The specific work-related psychosocial factors considered were job demands, support, job autonomy and job satisfaction. The conclusions of each review on one or more of the psychosocial/ musculoskeletal pain associations were extracted.

Results: 15 review articles were identified that considered one or more of the regional pain syndromes included in the study. For back pain, the most consistent conclusions (four reviews positive out of six) were with high job demands and low job satisfaction. The studies of upper limb pain were exclusively related to shoulder and/ or neck pain, and the most consistent positive conclusions were with high and low job demands (four reviews positive out of six and two reviews positive out of three, respectively). For knee pain, only a single review was identified. For individual reviews of back and upper limb pain, there were marked differences in the number of associations concluded to be positive between reviews.

Conclusions: The reasons for reviews coming to different conclusions included that they were often evaluating different bodies of evidence (according to their search criteria, the year when the review was conducted, the role that quality assessment played in whether studies contributed to evidence, and the combination of risk factors addressed in individual studies), but more important was whether the review specified explicit criteria for making conclusions on strength of evidence. These conclusions emphasise the importance of developing standardised methods for conducting such evaluations of existing evidence and the importance of new longitudinal studies for clarifying the temporal relationship between psychosocial factors and musculoskeletal pain in the workplace.

Regional musculoskeletal pain syndromes such as low back and shoulder pain, together with widespread body pain/fibromyalgia, are among the most common reasons for presentation to primary care and new consultations at rheumatology clinics. ${ }^{1-3}$ They are associated with high levels of perceived disability ${ }^{4}$ and subsequent workplace absenteeism. ${ }^{56}$ Economic analyses of the impact of these pain syndromes highlight the large scale of the problem, ${ }^{7}$ with, for example, 52 million lost working days per annum attributed to low back pain in the UK (which has a working population of 25 million). ${ }^{8}$

Taking low back pain as an example, prospective studies have established that workplace factors, such as mechanical load, working postures and whole body vibration, are strongly predictive of symptom onset. ${ }^{9-11}$ Interventions targeting certain aspects of physical work have resulted in some, albeit modest, reductions in the occurrence of regional musculoskeletal pain. ${ }^{12}$ Many studies have shown that psychosocial factors, such as low job satisfaction, ${ }^{13-16}$ low levels of support from colleagues and supervisors, ${ }^{17}{ }^{18}$ high job demands and low job control or low decision authority, ${ }^{19-21}$ are also associated with the reporting of pain. In many studies, psychosocial aspects were found to be more strongly predictive of pain and its progression than mechanical exposures. ${ }^{17} 22{ }^{23}$ Any such psychosocial factor that is potentially modifiable may be a suitable target in intervention studies. It is important therefore to assess whether there is agreement, arising from consistent evidence, that one or more of the workplace psychosocial factors measured are risk factors for regional pain syndromes

The objectives of this European League Against Rheumatism (EULAR)-sponsored project were to establish whether reviews provide consistent conclusions about associations between workplace psychosocial factors and musculoskeletal pain, and, if differences exist, to explore whether this is related to the methods used in the reviews. This project focused on regional pain syndromes of public health importance: back pain, shoulder/ neck/forearm pain and knee pain. The specific work-related psychosocial factors considered were job demands, support (from colleagues and supervisors), job autonomy and job satisfaction.

\section{METHODS}

\section{Search strategy}

A literature search was carried out in February 2007 using electronic databases Medline (from 1950), Embase (from 1988), PsycINFO and PubMed with the objective of identifying all English language review articles of studies examining the role of psychosocial aspects in relation to back, neck, shoulder, forearm and knee pain in occupational settings. The search was carried out separately for each pain syndrome. We adopted the strategy of searching for relevant articles and then 
Table 1 Description of review articles on back pain

\begin{tabular}{|c|c|c|c|c|c|}
\hline Review & $\begin{array}{l}\text { No of studies that included } \\
\text { psychosocial factors (types of } \\
\text { study: earliest and latest year } \\
\text { of inclusion) }\end{array}$ & Data sources & Main outcome measures & Populations & Search languages \\
\hline Ferguson \& Marras, $1997^{26}$ & 16 (2 CO and $14 \mathrm{CS}$ ) & Not indicated & $\begin{array}{l}\text { Low back pain or discomfort } \\
\text { or injury, or lost/restricted } \\
\text { time }\end{array}$ & $\begin{array}{l}\text { No restrictions } \\
\text { indicated }\end{array}$ & English \\
\hline Davis \& Heany, $2000^{32}$ & $\begin{array}{l}62 \text { (14 C0, } 1 \text { CC, } 47 \text { CS: 1973- } \\
98)\end{array}$ & $\begin{array}{l}\text { Medline, PsycINF0, Institute for } \\
\text { Scientific Information }\end{array}$ & $\begin{array}{l}\text { Incident or prevalent low } \\
\text { back pain }\end{array}$ & Not indicated & English \\
\hline Hoogendoorn et al, $2000^{29}$ & 13 (11 C0, 2 CC: 1949-97) & $\begin{array}{l}\text { Medline, Embase, PsycLIT, } \\
\text { NIOSHTIC, ISDOC, HSELINE }\end{array}$ & $\begin{array}{l}\text { Symptoms or signs of non- } \\
\text { specific back pain (and } \\
\text { including consequences of } \\
\text { back pain) }\end{array}$ & $\begin{array}{l}\text { General and working } \\
\text { populations }\end{array}$ & $\begin{array}{l}\text { English, Dutch, } \\
\text { German, French }\end{array}$ \\
\hline Hartvigsen, et al, $2004^{28}$ & 40 (40 C0: 1990-2002) & Medline, PsycINFO, OSH-ROM & $\begin{array}{l}\text { Low back pain and } \\
\text { consequences }\end{array}$ & $\begin{array}{l}\text { General and working } \\
\text { populations }\end{array}$ & English \\
\hline
\end{tabular}

CC, case-control; CO, cohort; CS, cross-sectional.

identifying which ones were review articles rather than, in the first instance, only searching for review articles.

In Medline and Embase databases, the search on back pain was carried out in several steps using keywords: (i) "back" or "low back" or "sciatica" or "limb\$"; (ii) "pain" or "disorder" or "disability" or "ache"; (iii) "work\$" or "occupation\$" or "job" or "employment\$"; (iv) "psychosocial" or "demand" or "control" or "strain" or "stress" or "hectic" or "support" or "satisfaction" or "content" or "load" or "ambiguity" or "monoton\$" or "mood" or "self rated health"; (v) "review" or "cross-sectional" or "case-control" or "longitudinal" or "cohort" or "prospective" or "follow up". Thereafter the intersection of the results of these searches (ie, articles identified by each of these searches) was identified. Keywords used in group (i) differed for each regional pain syndrome. For neck and shoulder pain, the keywords "neck" or "shoulder" or "upper limb" or "cervic\$" or "CANS" (complaints of arm, neck and shoulder) or "upper extremity" or, for forearm pain, the terms "forearm" and "arm" were used, and, for knee pain, "knee" or "lower extremity" or "leg" or "lower limb". In PsycINFO, a search was carried out separately for each pain syndrome using the keywords mentioned in step (i) above in combination with the words "ache" or "pain" or "disorder\$" and "psychosocial" or "demand" or "control" or "satisfaction" or "support" or "mood". In PubMed, a search was carried out separately for each pain syndrome using the same search procedure as for PsycINFO. Duplicates were removed from the results.

\section{Eligibility for inclusion in the review}

All the articles were screened in the following order: title, abstract and then the full text. In addition, the list of references was screened for further articles. Reviews conducted only on consequences and outcomes such as hospitalisation and sickness absence due to musculoskeletal disorders were excluded from the study. For reviews eligible to be included in this study, information was extracted on the regional musculoskeletal pains covered, search strategy used, studies identified, health outcomes measured, and exposures assessed. Information was also recorded on any quality assessment undertaken of individual studies, the methods used, and how this information was incorporated in the review.

\section{Presentation of data}

We summarised the conclusion of each review on the basis of published data. These represent the conclusions of the authors. If the authors of the original reviews indicated that the evidence was moderate or strong, we considered that to represent a positive association (indiciated by + in tables). If the authors concluded that there was only some, little or no evidence or if they did not clearly state a conclusion on the evidence available, we considered that not to be a positive association (0). If the authors concluded that there was evidence that there was not an association (as opposed to lack of evidence), this is indicated by $0^{*}$. If an individual review did not include consideration of a specific psychosocial factor, this is indicated by - in the tabulated results.

\section{RESULTS}

A total of 943 articles were found for back pain, 793 for shoulder and neck pain, 230 for forearm pain and 343 for knee pain. From these, 15 review articles were identified that considered one or more of the regional pain syndromes, back pain, neck/shoulder/ forearm pain and knee pain. Two reviews ${ }^{24} 25$ considered more than one regional pain syndrome from which it was not possible to extract the data and related conclusions for individual pain syndromes, and were not considered further. There were thereafter seven review articles that included consideration of psychosocial influences on back pain, six review articles of shoulder, neck or forearm pain, and one review article of knee pain.

\section{Low back pain}

Seven reviews focused exclusively, or included information separately, on low back pain (table 1). In total, 106 primary 
Table 2 Conclusions of review articles assessing the relationship between psychosocial work-related factors and back pain

\begin{tabular}{|c|c|c|c|c|c|}
\hline \multirow[b]{2}{*}{ Review } & \multicolumn{2}{|c|}{ Work demand } & \multirow{2}{*}{$\begin{array}{l}\text { Low work } \\
\text { control }\end{array}$} & \multirow{2}{*}{$\begin{array}{l}\text { Low work } \\
\text { support }\end{array}$} & \multirow{2}{*}{$\begin{array}{l}\text { Low job } \\
\text { satisfaction }\end{array}$} \\
\hline & High $\dagger$ & Low & & & \\
\hline $\begin{array}{l}\text { Bongers et al, } \\
1993^{33}\end{array}$ & + & + & 0 & + & 0 \\
\hline $\begin{array}{l}\text { Ferguson } \& \\
\text { Marras, } 1997^{26} *\end{array}$ & + & 0 & + & + & + \\
\hline $\begin{array}{l}\text { Lagerstrom et al, } \\
1998^{31}\end{array}$ & 0 & 0 & - & 0 & 0 \\
\hline $\begin{array}{l}\text { Hoogendoorn et al, } \\
2000^{29}\end{array}$ & 0 & 0 & 0 & + & + \\
\hline $\begin{array}{l}\text { Davis and Heaney, } \\
2000^{32}\end{array}$ & + & 0 & 0 & 0 & + \\
\hline Linton, $2001^{27}$ & + & + & 0 & + & + \\
\hline Hartvigsen et al, & - & - & - & $0^{*}$ & - \\
\hline
\end{tabular}

$2004^{28}$

+ , strong or moderate evidence; 0 , insufficient/no evidence; $0^{*}$, evidence against an association; -, not considered.

†Includes "stress".

\$Associations considered positive if at least $50 \%$ of the studies presented in the review showed a positive association between psychosocial factors and back pain. -This article considered 30 psychosocial variables grouped as: perception of work, organisational aspects of work, social support at work, and stress at work. Only social support at work maps sufficiently closely to the domains considered in the present study.

study reports were included, of which 43 had longitudinal aspects to the design.

Linton $^{27}$ and Hartvigsen et $a^{28}$ considered only cohort studies, Hoogendoorn et a ${ }^{29}$ considered case-control and cohort studies, while Bongers et $a l^{30}$ included cross-sectional and cohort studies. Three other reviews included all types of epidemiological studies in their review (Ferguson and Marras, ${ }^{26}$ Lagerstrom et al, ${ }^{31}$ Davis and $\mathrm{Heane}^{32}$ ). The review carried out by Lagerstrom et al ${ }^{31}$ was restricted to studies conducted on a specific occupational group (nurses), and the remaining reviews were conducted on both general and working populations or did not mention any restrictions. Hartvigsen et $a l^{28}$ identified 30 different psychosocial variables at work and grouped them into four categories: perception of work, organisational aspects of work, social support at work, and stress at work. Only the category "social
Table 4 Conclusions of review articles assessing the relationship between psychosocial work-related factors and neck/shoulder and forearm pain

\begin{tabular}{|c|c|c|c|c|c|}
\hline \multirow[b]{2}{*}{ Review } & \multicolumn{2}{|c|}{$\begin{array}{l}\text { Work } \\
\text { demand }\end{array}$} & \multirow{2}{*}{$\begin{array}{l}\text { Low work } \\
\text { control }\end{array}$} & \multirow{2}{*}{$\begin{array}{l}\text { Low work } \\
\text { support }\end{array}$} & \multirow{2}{*}{$\begin{array}{l}\text { Low job } \\
\text { satisfaction }\end{array}$} \\
\hline & High & Low & & & \\
\hline $\begin{array}{l}\text { Bongers et al, } \\
1993^{33}\end{array}$ & + & + & 0 & 0 & 0 \\
\hline $\begin{array}{l}\text { Van Der Windt } \\
\text { et al, } 2000^{37}\end{array}$ & 0 & - & 0 & 0 & 0 \\
\hline $\begin{array}{l}\text { Malchaire et al, } \\
2001^{34}\end{array}$ & + & + & 0 & 0 & 0 \\
\hline Ariens et al, $2001^{35}$ & 0 & - & 0 & 0 & 0 \\
\hline $\begin{array}{l}\text { Bongers et al, } \\
2002^{30}\end{array}$ & + & 0 & 0 & 0 & 0 \\
\hline Walker-Bone et al, & + & - & + & 0 & 0 \\
\hline
\end{tabular}

$2003^{36}$

+ , strong or moderate evidence; 0 , insufficient evidence or no evidence; -, not considered.

support at work" clearly links to the psychosocial domains included in the present study. Furthermore, the inclusion of variables under the same general psychosocial heading differed between reviews: for example, variables included in the group "social support at work" by Bongers et a ${ }^{133}$ were limited to "social support from supervisors and colleagues", whereas Hartvigsen et $a l^{28}$ considered a broader definition including "recognition and respect, social relations, relationships at work, others listening and external support".

Not all reviews mentioned the "disease" or "symptom" terms they used to search for articles (Ferguson and Marras ${ }^{26}$ ) nor specified what search terms they had used (eg, Bongers et al ${ }^{33}$ mentions only "musculoskeletal disorders"). Others stated that they had searched for articles on back pain and/or low back pain (Lagerstrom et al, ${ }^{31}$ Davis and Heaney, ${ }^{32}$ Linton $^{27}$ ) alone or in combination with consequences such as "disabilities", "disease", "pathology" (Hartvigsen et a ${ }^{28}$ ). Hoogendoorn et al ${ }^{29}$ used additional, specific, back pain-related terms "back pain", "low back pain", "lumbago", "backache", and conditions associated with back pain, namely, "intervertebral disc displacement", "hernia", "herniated disc", "sciatica", "disc pain".

Table 3 Description of review articles on neck/shoulder and forearm pain

\begin{tabular}{|c|c|c|c|c|c|}
\hline Review & $\begin{array}{l}\text { No of studies that included } \\
\text { psychosocial factors }\end{array}$ & Data sources & Main outcome measures & Populations & Languages considered \\
\hline Bongers et al, $1993^{33}$ & 15 (5 C0, 10 CS) (1973-92) & $\begin{array}{l}\text { Medline, OSH-ROM, CISDOC, } \\
\text { PsycINF0, manual searching }\end{array}$ & $\begin{array}{l}\text { Neck pain, neck disorder and } \\
\text { shoulder pain }\end{array}$ & $\begin{array}{l}\text { General and working } \\
\text { populations }\end{array}$ & English \\
\hline $\begin{array}{l}\text { Van der Windt et al, } \\
2000^{37}\end{array}$ & $29 *(26$ CS, 3 CC) (1966-98) & $\begin{array}{l}\text { Medline, Embase, PsycLIT, } \\
\text { Cinahl }\end{array}$ & Shoulder (joint) pain & No restrictions indicated & English \\
\hline Ariens et al, $2001^{35}$ & 29 (1 C0, 28 CS) (1966-97) & $\begin{array}{l}\text { Medline, Embase, PsycLIT, } \\
\text { SportDiscus, HSELINE, CISDOC } \\
\text { NIOSHTIC }\end{array}$ & Neck pain & $\begin{array}{l}\text { Community or working } \\
\text { populations }\end{array}$ & English, Dutch, German \\
\hline Malchaire et al, $2001^{34}$ & $64 \uparrow(7 \mathrm{CO}, 57 \mathrm{CS})$ & Not indicated & $\begin{array}{l}\text { Neck, shoulder, hand and } \\
\text { wrist pain }\end{array}$ & No restrictions indicated & English \\
\hline Bongers et al, $2002^{30}$ & $\begin{array}{l}28 \text { (1 CO, } 1 \text { CC, } 26 \text { CS) (1980- } \\
99)\end{array}$ & $\begin{array}{l}\text { Medline, PsycINF0, Ergonomics } \\
\text { Abstracts, OSH-ROM, manual } \\
\text { searching }\end{array}$ & $\begin{array}{l}\text { Shoulder, elbow, hand and } \\
\text { wrist pain }\end{array}$ & No restrictions indicated & English \\
\hline Walker-Bone et al, $2003^{36}$ & $\begin{array}{l}14(2 \text { CO, } 2 \text { CC, } 10 \text { CS) (1980- } \\
2001)\end{array}$ & Medline and Embase & $\begin{array}{l}\text { Neck pain, shoulder pain, } \\
\text { upper limb pain, elbow pain, } \\
\text { wrist pain, hand pain + } \\
\text { specific upper limb diagnoses }\end{array}$ & $\begin{array}{l}\text { General and working } \\
\text { populations }\end{array}$ & Not stated \\
\hline
\end{tabular}

*Between 11 and 14 studies included each of the individual psychosocial factors considered.
†Of which, 29 studies considered psychosocial factors of interest relating to the neck/shoulder.

CC, case-control; CO, cohort; CS, cross-sectional. 
Table 5 Description of review article on knee pain

\begin{tabular}{llllll}
\hline Review & $\begin{array}{l}\text { No of studies that included } \\
\text { psychosocial factors }\end{array}$ & Data sources & $\begin{array}{l}\text { Main outcome } \\
\text { measures }\end{array}$ & Populations & $\begin{array}{l}\text { Search } \\
\text { languages }\end{array}$ \\
\hline$D^{\prime}$ Souza et al, $2005^{38}$ & $4(3 \mathrm{CS} 1 \mathrm{CO})$ & PubMed & Knee pain & Not indicated & English \\
\hline
\end{tabular}

CO, cohort; CS, cross-sectional.

All except one review (Ferguson and Marras ${ }^{26}$ ) formally assessed the quality of included studies. However, the criteria used for the assessment varied across reviews. Some considered general markers of quality-for example, longitudinal study design (Bongers et al ${ }^{33}$ ) - while Davis \& Heaney ${ }^{32}$ considered control of confounding, timing of exposure and outcome, and quality of psychosocial assessment. Hartvigsen et $a l^{28}$ assigned a score using nine criteria: studies scored highly if (1) the purpose of the study was clearly stated, (2) features of the study population were clearly described, (3) the response rate was at least $80 \%$ at baseline and reported at follow-up, (4) validated instruments were used for psychosocial factors, (5) data on physical workload were collected, (6) there was a clear definition of low back pain, (7) data on outcome were collected at least once during 1 year, (8) data analysis was multivariable with control of confounding, and (9) outcome measures reported were presented with $95 \%$ CIs. Study quality was assessed by a single reviewer in most of the reviews, except that carried out by Hoogendoorn et al, ${ }^{29}$ who used two reviewers for the assessment and involved a third reviewer in the case of disagreement.

Most of the reviews conducted found evidence for an association between at least two of the psychosocial factors considered and back pain (table 2). The most consistent conclusion across reviews was for high job demands, low job satisfaction (four reviews positive out of six for each) and low work support (four reviews positive out of seven). Fewer reviews concluded that there were positive associations with low job demands (two reviews positive out of six) or low job autonomy (one positive review out of five).

\section{Neck/shoulder and forearm pain}

Six reviews were retrieved that considered neck, shoulder and/or forearm pain; table 3 provides details of these reviews. In total, they included 79 primary study reports, of which six were indicated as being from longitudinal studies.

No restrictions to the study populations included were mentioned in three reviews (Bongers et al, ${ }^{30}$ Malchaire et al, ${ }^{34}$ $\mathrm{V}$ an der Windt et $a^{l^{37}}$ ). Two authors specifically included studies conducted on working and general populations (Bongers et al, ${ }^{33}$ Ariens et $\left.a^{35}\right)$. Walker-Bone et $a l,{ }^{36}$ although stating that it was a review of neck and upper limb disorders in the general population, did include data from workplace studies.

Two of the reviews were on neck pain, one on shoulder pain and four were on shoulder and neck symptoms (with or without other upper limb conditions). It was common for the symptom search terms to be restricted to "neck pain" and/or

Table 6 Conclusions of review article assessing the relationship between psychosocial work-related factors and knee pain

\begin{tabular}{llllll}
\hline \multirow{2}{*}{ Review } & \multicolumn{2}{l}{ Work demand } & $\begin{array}{l}\text { Low work } \\
\text { control }\end{array}$ & $\begin{array}{l}\text { Low work } \\
\text { support }\end{array}$ & $\begin{array}{l}\text { Low job } \\
\text { satisfaction }\end{array}$ \\
\hline D'Souza et al, & - & - & - & - & 0 \\
$2005^{38}$ & & & & - & 0
\end{tabular}

+ , Significant association; 0 , no association or insufficient evidence; - , not considered. "shoulder pain"/"shoulder joint pain" (Ariens et al, ${ }^{35}$ van der Windt et $\left.a l^{37}\right)$, but Bongers et $a^{133}$ did not specify further than "musculoskeletal disease", and Malchaire et al ${ }^{34}$ did not specify search terms further than "studies orientated towards the neck and/or shoulder". Bongers et al ${ }^{30}$ and Walker-Bone et al ${ }^{36}$ used more detailed search terms to identify a variety of upper limb musculoskeletal disorders not solely related to the neck/ shoulder.

Almost all reviews formally assessed the quality of included studies, and the assessment criteria used in the reviews showed some consistency. Van der Windt et $a l^{37}$ Ariens et $a l^{35}$ and Bongers et $a^{\beta 3}$ used the same checklist with slight modifications. This checklist scored studies more highly when there was a clearly stated study objective, the study population was described and had high participation rates, when information was collected on both psychosocial and physical aspects of work that was multidimensional and (for the latter) included observation, when exposure assessment was more extensive (eg, included leisure time and past exposures), when the outcome assessment included disability and was blind to exposure status, and when analysis was multivariable, included adjustment for potential confounders and results were presented as effect measures with confidence intervals. Malchaire et $a^{34}$ did not give any details about quality assessment, and, although Walker-Bone et $a^{l^{36}}$ discussed the relative merits of certain aspects of study design and methods, they did not carry out a formal review of the quality of studies included. When carried out, assessment of quality of the studies was performed by two persons (Hoogendoorn et al, ${ }^{29}$ Van der Windt et al, ${ }^{37}$ Ariens et $a l,{ }^{35}$ Bongers et $\left.a l^{30}\right)$.

The most consistent conclusion for neck/shoulder pain related to high work demands (four out of six reviews concluded that there was an association) and low job demands (two from three reviews positive) (table 4). Low work demands included jobs evaluated as monotonous or with insufficient use of skills. A single review found evidence about low work control (out of six reviews). None of six reviews that considered them found sufficient evidence in relation to either low work support or low job satisfaction. Two out of six reviews concluded that there was not sufficient evidence for any psychosocial factor studied (Van Der Windt et al,,$^{37}$ Ariens et $a^{35}$ ), and Bongers et al ${ }^{30}$ concluded that there was only evidence for high job demands.

\section{Knee pain}

Only one review article was found on the role of psychosocial aspects of work on the development of knee pain (table 5; D'Souza et $a l^{38}$ ). This review included five studies (four crosssectional, one prospective) that examined some aspect of the psychosocial environment. The report did not clearly state the psychosocial variables that it considered other than job satisfaction. The authors used the disease or symptom terms "lower extremity disorders", "lower extremity musculoskeletal disorders", and "hip/knee/ankle/foot", although all results on psychosocial factors were reported in the section on knee pain. An assessment of quality was made considering the study design, type of population, exposure and outcome 
measurement, control for confounding, and statistical analysis undertaken.

Psychosocial factors were considered in only five studies included in the review regarding the association with knee pain, and only one of the cross-sectional studies found a positive association between knee pain and job stress. There was therefore insufficient evidence to conclude that there was a relationship (table 6). Whether this review identified all studies that have examined the role of work-related psychosocial factors is not clear-it did not include any psychosocial-specific search terms, but there is certainly a paucity of individual studies in relation to this important regional pain.

\section{DISCUSSION}

Several reviews have been conducted to assess evidence for the role of psychosocial factors in the aetiology of both low back pain and shoulder/neck pain. The most consistent positive conclusions for low back pain have been for high work demands, low work support and low job satisfaction, and those for shoulder pain have been for both high work demands and low work demands-although for most of these associations there are almost as many reviews that did not conclude that an association existed. The consistency of findings for high work demands related to both back and shoulder/neck pain is of note in contributing to the evidence that there is likely to be common features in the aetiology of these regional syndromes and in identifying risk factors for intervention with the largest possible impact on outcome. There is a lack of a formal review specifically focused on knee pain-partly reflecting that there have been relatively few studies specifically examining the role of work-related psychosocial factors.

What therefore are the reasons for the lack of consistency in the conclusions from reviews?

\section{Differences in assessed evidence}

For both back and shoulder/neck pain, differences in methods, and in the dates when the reviews were conducted, resulted in different bodies of evidence being assessed. Although there was considerable overlap in the studies contributing to each review, there were also a substantial number of reports that contributed to only a single review. For back pain (seven reviews), two studies contributed to five reviews, six studies to four reviews, eight studies to three reviews, nineteen studies to two reviews, and 71 studies to just one review. For shoulder pain (six reviews), two studies contributed to five reviews, nine studies to three reviews, seventeen studies to two reviews, and 48 studies to a single review. Therefore, the overlap between reviews on assessed evidence is low, and the "count" of review conclusions we have made relates to evaluations of different bodies of evidence-although we have not assessed, nor was it always explicit, what influence individual studies had on the overall evaluation of evidence. In evaluating the evidence, several reviews have noted that there was a lack of consistency in how key aspects of the psychosocial environment, such as job demands, autonomy, and workplace support and job satisfaction, were measured in individual studies. There was variation in both the domains investigated and the approach to collecting domain-specific data. Reviews have also taken different approaches to classifying the types of psychosocial factors in aggregating the evidence. Furthermore, the strength of an association reported by individual studies may strongly depend on the set of predictors evaluated; studies simultaneously assessing the predictive value of several psychosocial factors (with possibly strong inter-relations) may show different associations from studies that reported only univariable associations. In reviews focusing on associations from models adjusted for other psychosocial variables, given the strong positive association between such variables, this is likely to translate into more conservative conclusions about the association of individual psychosocial factors with outcome. In contrast, the likelihood of a review concluding that there was a positive relationship with any psychosocial factor was not clearly related to the accumulation of evidence over time: early and late reviews alike concluded that there was evidence or not for some relationships between regional pain and work-related psychosocial factors.

\section{Differences in methods used for synthesising evidence}

Reviews differed markedly in how they assessed the evidence for a relationship; those with explicit and stringent criteria for assessing reported relationships were less likely to conclude that there was strong evidence. For example, in the evaluation of evidence in relation to neck/shoulder pain, the three reviews reporting generally negative results made the criteria explicit and required the highest standards of evidence in order to conclude that there was a moderate or strong relationship. In particular, Bongers et $a l^{30}$ and van der Windt et $a l^{37}$ required (a) conclusions to be made on the temporal relationship, (b) consistent findings across studies (defined as $75 \%$ of studies), (c) strong associations and (d) high quality of studies. Ariens et $a l,{ }^{35}$ similarly, required that there were "consistent findings in multiple high quality cohort and/or case-control studies" to conclude that there was strong evidence for an association. In a research area in which there are methodological issues about the measurement of psychosocial factors and the reporting and timing of the outcome, and in which many of the studies are cross-sectional, these standards represent a formidable, albeit achievable, hurdle.

\section{Differences in quality assessment}

Some, but not all, reviews undertook an assessment of quality of individual studies. However, among the reviews assessing quality, there was little consistency in how this information was then used to assess evidence overall. For example, in the reviews of neck pain, van der Windt et $a^{l^{37}}$ only considered studies with a methodological score above the median when coming to conclusions, whereas Bongers et $a^{30}$ stated that studies with scores more than $60 \%$ of the maximum "contribute more to the conclusions than studies with a lower score". Ariens et al ${ }^{35}$ considered high-quality studies to be those that "scored positively on at least $50 \%$ of the validity/precision items on the methodological quality list", and, in evaluating the strength of evidence, explicitly listed the necessary contribution of high and low quality studies. In the single knee pain review conducted, although there was an evaluation of study quality which influenced which studies were described, it is not clear how these quality scores then influenced the evaluation of evidence. $^{38}$ Methodological work to standardise both the evaluation of quality and the integration of this information into the assessment of evidence would benefit the conduct and interpretation of future reviews.

\section{Importance of longitudinal studies}

For low back pain, the majority of reviews concluded that there were associations between high work demands, low work support (from colleagues and supervisors), low job satisfaction 
and symptoms. Many of these reviews were based, however, on predominantly case-control and cross-sectional studies. The most recent review, based only on prospective studies and with defined methods for assessing the strength of association and consistency of evidence, examined the role of low social support and concluded that there was moderate evidence against such an association. ${ }^{28}$ For shoulder/neck pain, most reviews concluded that there was evidence of an association between such symptoms (which were principally neck/shoulder pain) and both high and low work demands. There were far fewer prospective studies examining shoulder/neck pain than back pain, and thus the conclusions of all reviews were primarily based on cross-sectional and case-control studies. Two out of three reviews that set the highest standards for strength of evidence concluded that there was not sufficient evidence for an association with high work demands. ${ }^{35} 37$ This highlights the importance of conducting longitudinal studies in this area and the limited usefulness of further cross-sectional studies in any setting.

\section{Interaction between risk factors}

In this review of reviews, we have considered only psychosocial factors; indeed most of the reviews and individual studies have considered psychosocial factors in isolation. One of the consistent conclusions across reviews is the role of job demands in low back pain and neck/shoulder disorders. In contrast, "job strain" (high demands and low control) has either not been reported or there are inconsistent findings. While high job demands may indicate the importance of psychosocial factors, they may equally reflect jobs with high physical demands, and indeed such demands have been related to regional musculoskeletal pain syndromes including those of the low back and shoulder. ${ }^{39}$ Further, it is likely that there will be interactions among some of the psychosocial factors (eg, job demands with job satisfaction, job control or psychological factors), but, partly because of issues of statistical power, such interactions have rarely been examined within individual studies. These will be important issues for future studies to consider in determining the role of psychosocial factors; understanding their interrelationship will be crucial in determining what interventions may be appropriate to reduce the onset of associated symptoms.

In summary, this review of workplace psychosocial factors on regional musculoskeletal pain reviews has demonstrated that the majority of reviews of psychosocial factors in relation to low back pain and shoulder pain conclude that there is evidence for a relationship with one or more specific factors. In particular, high work demands have been associated with both of these regional pain syndromes. There were, however, considerable differences in conclusions between individual reviews. The reasons for reviews coming to different conclusions included that they were often evaluating different bodies of evidence (according to their search criteria, the year when the review was conducted, the role that quality assessment played in whether studies contributed to evidence, and the combination of risk factors addressed in individual studies) and using the information in different ways (eg, via quality assessment), but more important was whether the review specified explicit criteria for making conclusions on strength of evidence. This study emphasises the importance of developing standardised methods for conducting such evaluations of existing evidence and the importance of new longitudinal studies for clarifying the temporal relationship between psychosocial factors and musculoskeletal pain in the workplace.
Acknowledgements: We thank the European League Against Rheumatism for funding this project. We are also grateful to those who contributed their time commenting on drafts of the manuscript (Dr Gareth T Jones, University of Aberdeen) and contributing to discussions (Professor H Riihimaki, Institute of Occupational Health, Helsinki).

Competing interests: None.

\section{REFERENCES}

1. Turk DC, Rudy TF. Neglected factors in chronic pain treatment outcome studies: referral patterns, failure to enter treatment, and attrition. Pain 1990;43:7-25.

2. Mäntyselkä $\mathbf{P}$, Kumpusalo $E$, Ahonen R, Kumpusalo A, Kauhanen J, Viinamäki $H$, et al. Pain as a reason to visit the doctor. A study in Finnish primary health care. Pain 2001:89:175-80.

3. Symmons D, Asten P, McNally R, Webb R. Health needs assessments for musculoskeletal disease: the first step-estimating the number of incident and prevalence cases. Chesterfield: Arthritis Research Campaign, 2002.

4. de Gier M, Peters ML, Vlaeyen JW. Fear of pain, physical performance, and attentional processes in patients with fibromyalgia. Pain 2003;104:121-30.

5. Assefi NP, Coy TV, Uslan D, Smith WR, Buchwald D. Financial, occupational, and personal consequences of disability in patients with chronic fatigue. J Rheumatol 2003;30:804-8.

6. Kivimäki M, Leino-Arjas $P$, Kaila-Kangas L, Virtanen M, Elovainio M, Puttonen $S$, et al. Sickness absence as a prognostic outcome measure for fibromyalgia: an observational study. Ann Rheum Dis 2007;66:65-9.

7. Dagenais S, Caro J, Haldeman S. A systematic review of low back pain cost of illness studies in the United States and internationally. Spine J 2008;8:8-20.

8. Palmer KT, Walsh K, Bendall H, Cooper C, Coggon D. Back pain in Britain: comparison of two prevalence surveys at an interval of 10 years. BMJ 2000;320:1577-8.

9. Hoogendoorn WE, van Poppel MN, Bongers PM, Koes BW, Bouter LM. Physical load during work and leisure time as risk factors for back pain. Scand J Work Environ Health 1999;25:387-403.

10. The National Research Council. Musculoskeletal disorders and the workplace: Iow back and upper extremities. Washington, DC: National Academy Press, 2001. http:// www.nap.edu/openbook.php?record_id=10032\&page=R2 (accessed 3 Apr 2009).

11. Harkness EF, Macfarlane GJ, Nahit ES, Silman AJ, McBeth J. Risk factors for newonset low back pain amongst cohorts of newly employed workers. Rheumatology (Oxford) 2003:42:959-68.

12. Linton SJ, van Tulder MW. Preventive interventions for back and neck pain problems: what is the evidence? Spine 2001;26:778-87.

13. Biering-Sorensen F, Thomsen C. Medical, social and occupational history as risk indicators for low-back trouble in a general population. Spine 1986;11:720-5.

14. Bergenudd $\mathbf{H}$, Nilsson B. Back pain in middle age; occupational workload and psychologic factors: an epidemiologic survey. Spine 1988;13:58-60.

15. Papageorgiou AC, Croft PR, Thomas E, Silman AJ, Macfarlane GJ. Psychosocial risks for low back pain: are these related to work? Ann Rheum Dis 1998;57:500-2.

16. Papageorgiou AC, Macfarlane GJ, Thomas E, Croft PR. Psychosocial factors in the workplace-do they predict new episodes of low back pain? Evidence from the South Manchester Back Pain Study. Spine 1997;22:1137-42.

17. Bigos SJ, Battie MC, Spengler DM, Fisher LD, Hansson TH. A prospective study of work perceptions and psychosocial factors affecting the report of back injury. Spine 1991;16:1-6.

18. Riihimaki H, Viikari-Juntura E, Moneta G, Kuha J, Videman T, Tola S. Incidence of sciatic pain among men in machine operating, dynamic physical work, and sedentary work. Spine 1994;19:138-42.

19. Josephson M, Hagberg M, Hjelm EW. Self reported physical exertion in geriatric care. A risk indicator of low back symptoms? Spine 1996;21:2781-5.

20. Hoogendoorn WE, Bongers PM, de Vet HC, Houtman IL, Ariens GA, Van Mechelen W, et al. Psychosocial work characteristics and psychological strain in relation to lowback pain. Scand J Work Environ Health 2001;27:258-67.

21. Latza U, Karmaus W, Sturmer T, Steiner M, Neth A. Cohort study of occupational risk factors of low back pain in construction workers. Occup Environ Med 2000;57:28-34.

22. Jansen JP, Morgenstern $H$, Burdorf $A$. Dose-response relations between occupational exposures to physical and psychosocial factors and the risk of low back pain. Occup Environ Med 2004;61:972-9.

23. Eriksen W, Bruusgaard D, Knardahl S. Work factors as predictors of intense or disabling low back pain; a prospective study of nurses' aides. Occup Environ Med 2004;61:398-404.

24. Linton SJ. A review of psychological risk factors in back and neck pain. Spine 2000;25:1148-56.

25. Woods V. Work-related musculoskeletal health and social support. Occup Med 2005;55:177-89.

26. Ferguson SA, Marras WS. A literature review of low back disorder surveillance measures and risk factors. Clin Biomech 1997;12:211-26.

27. Linton SJ. Occupational and psychological factors increases the risk for back pain: a systematic review. J Occup Rehabil 2001;11:53-66.

28. Hartvigsen J, Lings S, Leboeuf-Yde, Bakketeig L. Psychosocial factors at work in relation to low back pain and consequences of low back pain: a systematic, critical review of prospective cohort studies. Occup Environ Med 2004;61:e2. 
29. Hoogendoorn WE, Poppel van MN, Bongers PM, Koes BW, Bouter LM. Systematic review of psychosocial factors at work and private life as risk factors for back pain. Spine 2000;25:2114-25.

30. Bongers PM, Kremer AM, Laak J ter. Are psychosocial factors, risk factors for symptoms and signs of the shoulder, elbow, or hand/wrist? A review of the epidemiological literature. Am J Ind Med 2002;41:315-42.

31. Lagerstrom M, Hansson T, Hagberg M. Work-related low-back problems in nursing. Scand J Work Environ Health 1998;24:449-64.

32. Davis KG, Heaney CA. The relationship between psychosocial work characteristics and low back pain: underlying methodological issues. Clin Biomech 2000;15:389-406.

33. Bongers PM, de Winter CR, Kompier MA, Hildebrandt VH. Psychosocial factors at work and musculoskeletal disease. Scand J Work Environ Health 1993:19:297-312.

34. Malchaire J, Cock N, Vergracht S. Review of the factors associated with musculoskeletal problems in epidemiological studies. Int Arch Occup Environ Health 2001;74:79-90.
35. Ariens GAM, van Mechelen W, Bongers PM, Bouter LM, van der Wal G. Psychosocial risk factors for neck pain: a systematic review. Am J Ind Med 2001;39:180-93.

36. Walker-Bone KE, Palmer KT, Reading I, Cooper C. Soft-tissue rheumatic disorders of the neck and upper limb: prevalence and risk factors. Semin Arthritis Rheum 2003;33:185-203.

37. van der Windt DAWM, Thomas E, Pope DP, de Winter AF, Macfarlane GJ, Bouter LM, et al. Occupational risk factors for shoulder pain: a systematic review. Occup Environ Med 2000;57:433-42.

38. d'Souza JC, Franzblau A, Werner RA. Review of epidemiologic studies on occupational factors and lower extremity musculoskeletal and vascular disorders and symptoms. J Occup Rehabil 2005;15:129-65.

39. National Institute of Occupational Safety and Health (NIOSH). Musculoskeletal disorders and workplace factors: a critical review of epidemiologic evidence for workrelated musculoskeletal disorders of the neck, upper extremity and low back. NIOSH Publication No 97-141. Cincinnati, OH: NIOSH. http://www.cdc.gov/niosh/docs/97141/ (accessed 26 Mar 2009). 